\title{
PEDIATRIC ORIGINAL ARTICLE Height, adiposity and hormonal cardiovascular risk markers in childhood: how to partition the associations?
}

\author{
JCK Wells ${ }^{1}$ and TJ Cole ${ }^{2}$
}

OBJECTIVE: Obesity is associated with rapid growth during childhood. There is uncertainty over how to adjust for body size, when using adiposity as a proxy for cardiovascular risk. We studied associations of height, body composition (by dual-energy X-ray absorptiometry) and cardiovascular risk markers (insulin resistance (IR), leptin) in children.

METHODS: Using partial correlations in 172 children aged 7-12 years, we investigated associations of (a) fat mass with IR or leptin, adjusting for height or lean mass, and (b) height or lean mass with IR or leptin, adjusting for fat mass. Analyses were conducted both cross-sectionally at each age, and for changes between 7 and 12 years.

RESULTS: Height, fat mass, lean mass, IR and leptin were all inter-correlated at all ages. Although fat mass was strongly associated with IR and leptin, height was independently negatively associated with leptin (whole sample, adjusting for age: boys $r=-0.12$, girls $r=-0.13 ; P<0.001$ ). Independent of adiposity, height was also associated with insulin IR (whole sample, adjusting for age: boys $r=0.11$, girls $r=0.20 ; P<0.001$ ). When analysed by year of age, these associations tended to remain significant at older ages. Change in height from 7 to 12 years was also associated with change in IR (boys: $r=0.18, P<0.05 ;$ girls: $r=0.34, P<0.01$ ), independently of change in adiposity, with similar findings for lean mass.

CONCLUSIONS: During childhood, markers of cardiovascular risk have a complex profile, associated with growth as well as fat accumulation. Taller and faster-growing children have elevated risk markers, independently of their adiposity. These findings have implications for the interpretation of pediatric indices of adiposity that aim to adjust for body size. Adiposity indices that perform best at summarizing metabolic risk may not be those that perform best at understanding the developmental aetiology of risk.

International Journal of Obesity (2014) 38, 930-935; doi:10.1038/ijo.2014.24

Keywords: BMl; cardiovascular risk; size adjustment; adiposity; leptin; insulin resistance

\section{INTRODUCTION}

Obesity is now well established to elevate the risk of chronic degenerative diseases, including type 2 diabetes, hypertension, cardiovascular disease (CVD) and some cancers. ${ }^{1,2}$ Although the main effects of these diseases are experienced in later life, childhood obesity appears to increase both short- and long-term health risks. ${ }^{3-5}$ Monitoring of nutritional status during childhood may potentially contribute to the reduction of these risks.

To address this issue, epidemiological studies have researched both the factors that predispose to childhood obesity, and the profile of CVD risk accumulation over time. In this context, the most widely studied index of nutritional status has been body mass index (BMI). ${ }^{6-8}$ However, BMI does not provide information on the relative proportions of fat and lean components in weight, ${ }^{9}$ hence, there is also interest in studying the accretion of fat and lean tissue through childhood, and exploring their association with the development of risk. ${ }^{10-12}$

The primary body composition outcomes investigated when 'going beyond' BMI are fat mass and lean mass (used here synonymously with fat-free mass). However, it has long been recognized that such data require some form of correction for body size. ${ }^{13-15}$ Individuals who have grown faster or for longer are expected to have greater absolute tissue masses, hence, size adjustment is required to assess whether a given individual is fatter or just larger. Whereas BMI adjusts weight for height, body composition data have conventionally been expressed in the format of 'percentage fat' (\%fat), which describes the proportion of fat in weight. ${ }^{13}$

The use of \%fat as an index of adiposity presents two problems, which remain poorly recognized. The first issue is that this approach directs undue attention to fat at the expense of lean. This is unfortunate, as while excess fat is associated with poorer health, variability in lean mass also contributes to the metabolic profile. ${ }^{16-18}$ The second issue is that \%fat is statistically problematic, as fat mass, when divided by weight, is present in both numerator and denominator. ${ }^{19,20}$ As absolute fat mass increases, $\%$ fat rises increasingly slowly, eventually trending towards an asymptote at around $60 \%$ fat. In obese individuals, even large gains or losses in adipose tissue mass may induce only small changes in \%fat. For example, if a person weighing $100 \mathrm{~kg}$ and comprising $50 \%$ fat gains $10 \mathrm{~kg}$ of fat, the $20 \%$ increase in absolute fat mass seems very modest when expressed as a change in \%fat, from 50 to $54.5 \%$. Furthermore, high \%fat values may reflect high adiposity and/or low lean mass. ${ }^{19}$ The proportion of fat in weight is therefore not an index of adiposity that is independent of body size.

In adults, many researchers resolve this problem by splitting BMI into two components, the lean mass index (LMI: lean mass/ height-squared) and the fat mass index (FMl: fat mass/heightsquared), each expressed in the same $\mathrm{kg} \mathrm{m}^{-2}$ units as BMI. This

${ }^{1}$ Childhood Nutrition Research Centre, UCL Institute of Child Health, London, UK and ${ }^{2}$ Centre for Paediatric Epidemiology and Biostatistics, UCL Institute of Child Health, University College, London, UK. Correspondence: Professor JCK Wells, Childhood Nutrition Research Centre, UCL Institute of Child Health, 30 Guilford Street, London, WC1N 1 EH, UK. E-mail: Jonathan.Wells@ucl.ac.uk 
approach, developed by Van Itallie et al., ${ }^{14}$ has two benefits: it adjusts tissue masses for an independent component of body size, while also keeping fat and lean outcomes separate. When this approach is adopted in children, however, an additional statistical issue becomes relevant.

$\mathrm{BMI}$ is calculated as weight/height-squared because this statistical adjustment has been found to generate an index of weight that is broadly independent of height. In some children's age groups, however, BMI may remain correlated with height. ${ }^{21,22}$ This could suggest that taller children are heavier even after standardizing for height, or it could indicate that statistical adjustment using the square of height is incompletely effective. Each of these arguments has been made. ${ }^{19,23}$ The issue becomes even more important if body composition is considered. Whereas lean mass tends to scale with height-squared in childhood as in adulthood, ${ }^{19,20,24}$ the power $(n)$ to which height must be raised to generate an index fat mass/height ${ }^{n}$ that is independent of height approaches 5 or 6 in childhood, ${ }^{19}$ although it may also vary with age. Fat mass index therefore remains correlated with height, that is, taller children have greater adiposity using this approach. ${ }^{19,23}$

Recently, this dilemma received attention in analyses of the EarlyBird cohort of children in Plymouth, UK, where data have been collected at sequential time points on each of body size, body composition and metabolic risk. ${ }^{25}$ These data allow investigation of how body composition data might best be expressed, in order to index CVD risk. In a recent publication on this cohort, Metcalfe et al. ${ }^{25}$ reported that BMI or FMI had stronger associations with leptin and insulin resistance (IR) than did indices of weight or fat mass that adjusted completely for height variability. They therefore proposed that height-normalized indices were not the optimal approach for expressing adiposity data. Instead, they argued that it is more appropriate to accept that taller children are fatter, and that it does not help to use statistical adjustments to hide this association.

In an invited commentary, we suggested that it may still be helpful to try to disentangle associations of size and adiposity with CVD risk, as each exposure may provide different information about the aetiological development of risk. ${ }^{26}$ If BMI indexes risk, but also remains positively correlated with height, then it appears that some of this metabolic risk derives from height and growth trajectory, independent of the risk deriving from adiposity.

As yet, however, the independent respective associations of fat and height with indicators of cardiometabolic risk have not been clearly determined. To enable investigation of this issue, Metcalfe et al. ${ }^{25}$ made their data available to us. In this paper, we therefore explore the independent associations of body size and body composition with CVD risk in the EarlyBird cohort. The aim was to gain greater insight into how these different exposures interact in accounting for CVD risk, and hence to improve understanding of what analyses may be done in future studies and how data may best be expressed.

\section{MATERIALS AND METHODS}

Data were available annually from 7 to 12 years for 152 boys and 120 girls, with a small loss of sample size ( 15 boys, $\sim 20$ girls, varying by trait) over the study period (see Table 1). The traits examined here were weight and height, fat mass and lean mass, measured by dual-energy X-ray absorptiometry, and fasting blood concentrations of insulin and leptin, two markers of CVD risk. The insulin data were obtained through a validated approach, HOMA2-IR, and represent a marker of peripheral IR. The details of the study design and data collection have been described previously. ${ }^{25}$

\section{Analyses}

Preliminary analyses showed that fat mass, leptin and IR were right-skewed, hence these variables were natural log-transformed to achieve normality. All subsequent analyses were conducted on these log-transformed values. All analyses were also conducted separately for boys and girls.
Table 1. Crude correlations of height with indices of weight, body composition and metabolic risk

\begin{tabular}{|c|c|c|c|c|c|c|c|}
\hline & $N$ & Weight & $B M I$ & $\begin{array}{l}\text { Fat } \\
\text { mass }\end{array}$ & $\begin{array}{l}\text { Lean } \\
\text { mass }\end{array}$ & Leptin & $\begin{array}{l}\text { Insulin } \\
\text { resistance }\end{array}$ \\
\hline \multicolumn{8}{|l|}{ Boys } \\
\hline \multicolumn{8}{|l|}{ Visit } \\
\hline 7 & 152 & 0.81 & 0.34 & 0.59 & 0.87 & 0.32 & $0.19^{*}$ \\
\hline 8 & 149 & 0.80 & 0.41 & 0.55 & 0.82 & 0.38 & $0.21^{*}$ \\
\hline 9 & 138 & 0.81 & 0.47 & 0.61 & 0.83 & 0.34 & 0.36 \\
\hline 10 & 140 & 0.80 & 0.50 & 0.62 & 0.81 & 0.43 & 0.41 \\
\hline 11 & 134 & 0.77 & 0.46 & 0.60 & 0.81 & 0.31 & $0.21^{*}$ \\
\hline 12 & 135 & 0.75 & 0.43 & 0.49 & 0.81 & 0.32 & 0.31 \\
\hline All adj. age & 751 & 0.73 & 0.42 & 0.58 & 0.84 & 0.35 & 0.26 \\
\hline \multicolumn{8}{|l|}{ Girls } \\
\hline \multicolumn{8}{|l|}{ Visit } \\
\hline 7 & 120 & 0.80 & 0.42 & 0.62 & 0.88 & 0.47 & 0.36 \\
\hline 8 & 102 & 0.80 & 0.49 & 0.65 & 0.89 & 0.44 & 0.44 \\
\hline 9 & 110 & 0.79 & 0.49 & 0.63 & 0.88 & 0.42 & 0.37 \\
\hline 10 & 110 & 0.78 & 0.51 & 0.62 & 0.87 & 0.48 & 0.51 \\
\hline 11 & 95 & 0.74 & 0.47 & 0.55 & 0.82 & 0.43 & 0.46 \\
\hline 12 & 97 & 0.75 & 0.49 & 0.62 & 0.84 & 0.53 & 0.49 \\
\hline All adj. age & 574 & 0.75 & 0.49 & 0.60 & 0.84 & 0.44 & 0.41 \\
\hline
\end{tabular}

Abbreviation: BMI, body mass index. Fat mass, leptin and insulin resistance are natural log-transformed. All adj. age-correlation in whole sample, partialling out the effect of age. All correlations are significant $P<0.001$ except $* P<0.025$.

Crude Pearson's correlations were calculated to establish associations of height with body composition, leptin and IR and also of fat mass and lean mass with leptin and IR. These correlations were first calculated for each age group separately, and then for all data combined, partialling out the effect of age. We also tested whether the sexes showed different associations between height and leptin or insulin resistance, by including a sex-interaction term.

Partial correlations were then calculated to establish the association of fat with CVD risk adjusting for height, and of height with CVD risk adjusting for fat. A similar approach was then used for body composition to establish the association of fat mass with CVD risk adjusting for lean, and of lean mass with CVD risk adjusting for fat. As BMI remains the index of adiposity most commonly used in large epidemiological studies, we also calculated the associations of height and lean mass with CVD risk, partialling out the effect of BMI. Again, these correlations were first calculated for each separate age group and then for all age groups combined, partialling out the effect of age.

We then calculated the change over time in each variable, as the difference between the 7-year and 12-year values. These changes are termed $\Delta$, for example $\Delta$ fat refers to the increase in fat mass between 7 and 12 years. These changes were calculated from the log-transformed start and end values for fat mass, leptin and IR. We first tested whether baseline leptin and IR were correlated with $\Delta$ height, $\Delta$ lean or $\Delta$ fat. We then calculated partial correlations to assess associations of $\Delta$ fat with CVD risk adjusting for $\Delta$ height or $\Delta$ lean, or of $\Delta$ height or $\Delta$ lean with $\Delta$ CVD risk adjusting for $\Delta$ fat.

\section{RESULTS}

Descriptive data on the cohort have been given previously. ${ }^{25}$ Height was significantly positively correlated with weight, BMI, fat and lean masses, leptin and IR at all ages in both sexes (Table 1). Thus, at any age, taller children have greater BMI and absolute tissue masses, and greater circulating levels of leptin and IR. In the whole sample, there were sex interactions in the association of leptin and IR with height, indicating that the correlation coefficients were significantly greater in girls than in boys (leptin: $P<0.001$; IR: $P<0.02)$. Supplementary Table S1 further shows that fat mass and lean mass were both positively associated with leptin and IR at all ages, and significantly so at most ages. Figure 1 summarizes the age-adjusted correlations of the three 
components of body size and composition (height, lean mass and fat mass) with the two metabolic outcomes (leptin and IR). All associations were highly significant in both sexes, $P<0.0001$.

Table 2 shows that at all ages, fat mass adjusted for height was correlated with both leptin and IR. In addition, height adjusted for fat mass was inversely associated with leptin. In boys, these correlations were significant at 7, 11 and 12 years and in the ageadjusted whole sample, while in girls, the correlations were significant at 8 and 10 years and in the age-adjusted whole sample. In girls but not boys, height adjusted for fat mass was positively associated with IR at 10 and 12 years. Table 2 also shows the associations of height with IR and leptin, partialling out the index of adiposity most widely used in clinical practice and research studies, BMI. Height shows independent associations with IR in both sexes, with the associations stronger at older ages. There is only weak evidence of an association of height with IR after adjustment for fat, and this association is positive, whereas that of height and leptin adjusted for fat mass is negative.

Table 3 shows that at all ages, fat mass adjusted for lean mass was correlated with leptin and IR. In boys at 11 and 12 years, and in girls at 8, 10 and 11 years, lean mass adjusted for fat mass was inversely associated with leptin. In girls aged 11 and 12 years, lean mass adjusted for fat mass was positively associated with IR.

Table 4a shows that baseline leptin and IR were not associated with $\Delta$ height in either sex. Baseline leptin was directly associated with $\Delta$ lean in girls, and inversely associated with $\Delta$ fat in both sexes. In girls, baseline IR was directly associated with $\Delta$ lean, and inversely associated with $\Delta$ fat. Table $4 \mathrm{~b}$ also shows correlations for changes $(\Delta)$ in the variables from 7 to 12 years. $\Delta$ BMI was positively associated with changes in all other traits. $\Delta$ height was positively associated with $\Delta$ lean and $\Delta$ fat, showing that children growing faster in height gained more fat and more lean. However, $\Delta$ lean and $\Delta$ fat were not correlated. Both $\Delta$ height and $\Delta$ lean were associated with $\Delta$ IR but not $\Delta$ leptin, whereas $\Delta$ fat was associated with both $\Delta$ leptin and $\Delta$ IR. Furthermore, $\Delta$ leptin was positively associated with $\Delta \mathrm{IR}$

Table 5 shows partial correlations, adjusting the associations between $\Delta$ fat and $\Delta$ cardiovascular risk markers for $\Delta$ height or $\Delta$ lean mass, and vice versa. Adjusting for $\Delta$ height, $\Delta$ fat was positively associated with $\Delta \mathrm{IR}$ and $\Delta$ leptin. Similarly, adjusting for $\Delta$ lean, $\Delta$ fat was positively associated with both $\Delta$ leptin and $\Delta$ IR. Thus, independently of growth in height or lean mass, increasing adiposity was associated with increased CVD risk. Adjusting for $\Delta$ fat, $\Delta$ height was associated with $\Delta$ IR but not with $\Delta$ leptin, while $\Delta$ lean was associated with $\Delta \mathrm{IR}$ in both sexes and

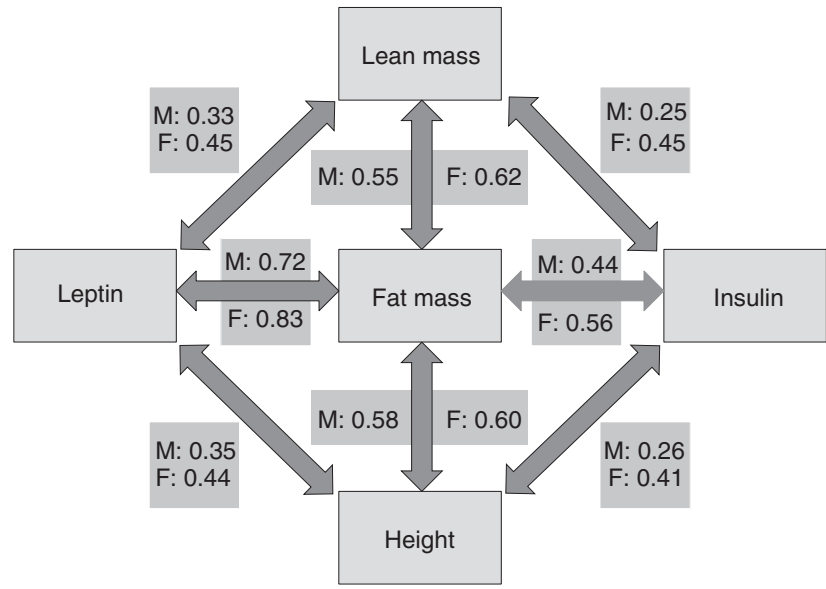

Figure 1. Age-adjusted correlations of height, lean mass or fat mass with leptin and insulin in the entire sample, presented separately for males (M) and females (F). Fat mass, insulin and leptin were natural log-transformed. All correlations $P<0.0001$. showed a borderline-significant association with $\Delta$ leptin in girls only. These results indicate that independent of increases in adiposity, growth in height or lean mass was associated with increasing $I R$.

\section{DISCUSSION}

These data indicate that taller children have greater absolute fat mass and leptin and IR, as described previously in the same cohort, with our analyses demonstrating that the crude association of height with leptin and IR is stronger in girls than in boys. ${ }^{25}$ However, height and lean mass also show associations with each of fat mass, leptin and IR. Disentangling their respective independent associations may help understand how best to express data on body composition in order to index and interpret metabolic risk.

Metcalf et al. ${ }^{25}$ argued that normalizing weight or fat mass for height 'obfuscates', and that the elevated metabolic risk of taller fatter children would be missed using this approach. We argued that part of the elevated risk in taller children might derive from their height, independently of their high adiposity, and that these different sources of risk are important to know about. ${ }^{26}$

Consistent with our predictions, our cross-sectional analyses show that while much of the variability in CVD risk can be attributed to adiposity, height also has associations with each of leptin (both sexes) and IR (girls only), that are independent of adiposity. From 11 years in boys, and at 8 and 11 years in girls, taller children have lower leptin, and taller girls at 10 and 12 years have greater IR. These trends are also significant in the whole sample, adjusting for age. These findings are broadly replicated for lean mass, such that adjusting for adiposity, older children with greater levels of lean mass have lower leptin, whereas older girls with more lean mass have greater IR.

The strong association of fat mass with leptin at every age, even after adjusting for height, is consistent with the notion that leptin acts as a signal of adiposity. ${ }^{27,28}$ The negative association of leptin

Table 2. Partial correlations for associations of leptin and insulin with fat adjusted for height, and with height adjusted for fat or BMI

\begin{tabular}{|c|c|c|c|c|c|c|}
\hline & \multicolumn{3}{|c|}{ Leptin } & \multicolumn{3}{|c|}{ Insulin } \\
\hline & $\begin{array}{l}\text { Fat adj. } \\
\text { height }\end{array}$ & $\begin{array}{l}\text { Height } \\
\text { adj. fat }\end{array}$ & $\begin{array}{c}\text { Height } \\
\text { adj. BMI }\end{array}$ & $\begin{array}{l}\text { Fat adj. } \\
\text { height }\end{array}$ & $\begin{array}{l}\text { Height } \\
\text { adj. fat }\end{array}$ & $\begin{array}{l}\text { Height } \\
\text { adj. BMI }\end{array}$ \\
\hline \multicolumn{7}{|l|}{ Boys } \\
\hline \multicolumn{7}{|l|}{ Visit } \\
\hline 7 & $0.68^{* *}$ & $-0.20^{* *}$ & 0.05 & $0.28^{* *}$ & -0.02 & 0.05 \\
\hline 8 & $0.61^{* *}$ & -0.07 & 0.12 & $0.41^{* *}$ & -0.10 & 0.07 \\
\hline 9 & $0.53^{* *}$ & -0.02 & 0.09 & $0.32^{* *}$ & 0.12 & $0.21^{*}$ \\
\hline 10 & $0.66^{* *}$ & -0.04 & 0.12 & $0.41^{* *}$ & 0.13 & $0.23^{*}$ \\
\hline 11 & $0.82^{* *}$ & $-0.36^{* *}$ & -0.04 & $0.40^{* *}$ & -0.07 & 0.04 \\
\hline 12 & $0.84^{* *}$ & $-0.29^{* *}$ & 0.03 & $0.41^{* *}$ & 0.04 & 0.16 \\
\hline All adj. age & $0.68^{* *}$ & $-0.12^{* *}$ & $0.09^{*}$ & $0.37^{* *}$ & 0.01 & $0.11^{* * *}$ \\
\hline \multicolumn{7}{|l|}{ Girls } \\
\hline \multicolumn{7}{|l|}{ Visit } \\
\hline 7 & $0.70 * *$ & -0.02 & $0.21^{*}$ & $0.47^{* *}$ & -0.00 & 0.14 \\
\hline 8 & $0.79^{* *}$ & $-0.19 * *$ & 0.10 & $0.38^{* *}$ & 0.15 & $0.25^{*}$ \\
\hline 9 & $0.74^{* *}$ & -0.27 & 0.08 & $0.38^{* *}$ & 0.02 & 0.15 \\
\hline 10 & $0.76^{* * *}$ & -0.06 & $0.20^{*}$ & $0.43^{* *}$ & $0.20^{*}$ & $0.32^{* * *}$ \\
\hline 11 & $0.88^{* *}$ & $-0.34^{* *}$ & 0.04 & $0.55^{* *}$ & 0.13 & $0.22^{*}$ \\
\hline 12 & $0.88^{* *}$ & -0.07 & 0.19 & $0.41^{* *}$ & $0.22 *$ & $0.28^{* *}$ \\
\hline All adj. age & $0.78^{* *}$ & $-0.13^{* *}$ & $0.12^{*}$ & $0.52^{* *}$ & $0.11^{*}$ & $0.20^{* *}$ \\
\hline
\end{tabular}

Abbreviation: $\mathrm{BMI}$, body mass index. Fat mass, leptin and insulin are natural log-transformed. All adj. age-correlation in whole sample, partialling out the effect of age . ${ }^{* *} P<0.001 ;{ }^{*} P<0.05$. 
with lean mass or height, which only emerged after adjusting for adiposity, suggests that leptin might further differentiate between fat and lean tissues, such that for a given quantity of fat mass, those with greater lean mass produce less leptin. Our longitudinal analyses show that baseline leptin is associated with the subsequent increase in lean mass, significant in girls only.

Table 3. Partial correlations for associations of leptin and insulin with fat adjusted for lean, and with lean adjusted for fat

\begin{tabular}{|c|c|c|c|c|}
\hline & \multicolumn{2}{|c|}{ Leptin } & \multicolumn{2}{|c|}{ Insulin } \\
\hline & Fat adj. lean & Lean adj. fat & Fat adj. lean & Lean adj. fat \\
\hline \multicolumn{5}{|l|}{ Boys } \\
\hline \multicolumn{5}{|l|}{ Visit } \\
\hline 7 & $0.63^{* *}$ & -0.10 & $0.18 *$ & 0.13 \\
\hline 8 & $0.60^{* *}$ & -0.01 & $0.42^{* *}$ & -0.11 \\
\hline 9 & $0.57^{* *}$ & -0.11 & $0.36^{* *}$ & 0.05 \\
\hline 10 & $0.67^{* *}$ & -0.04 & $0.43^{* * *}$ & 0.08 \\
\hline 11 & $0.81^{* *}$ & $-0.28^{*}$ & $0.42^{* *}$ & -0.10 \\
\hline 12 & $0.86^{* *}$ & $-0.41^{* *}$ & $0.41^{* * *}$ & 0.05 \\
\hline All adj. age & $0.68^{* * *}$ & $-0.13^{* *}$ & $0.38^{* *}$ & -0.01 \\
\hline \multicolumn{5}{|l|}{ Girls } \\
\hline \multicolumn{5}{|l|}{ Visit } \\
\hline 7 & $0.69^{* *}$ & -0.04 & $0.44^{* *}$ & 0.02 \\
\hline 8 & $0.80^{* * *}$ & $-0.23^{*}$ & $0.36^{* *}$ & 0.20 \\
\hline 9 & $0.70^{* *}$ & -0.12 & $0.34^{*}$ & 0.03 \\
\hline 10 & $0.77^{* * *}$ & $-0.20^{*}$ & $0.40^{* * *}$ & 0.16 \\
\hline 11 & $0.87^{* *}$ & $-0.32^{*}$ & $0.48^{* *}$ & $0.25^{*}$ \\
\hline 12 & $0.86^{* *}$ & -0.03 & $0.34^{*}$ & $0.29^{* *}$ \\
\hline All adj. age & $0.78^{* *}$ & $-0.13^{* *}$ & $0.40^{* *}$ & $0.17^{* *}$ \\
\hline
\end{tabular}

Table 4a. Longitudinal associations between body composition and metabolic risk from 7 to 12 years. Correlations between baseline leptin or insulin and change in size or body composition between 7 and 12 years

\begin{tabular}{|c|c|c|c|c|c|c|}
\hline & \multicolumn{2}{|c|}{$\Delta$ Height } & \multicolumn{2}{|c|}{$\Delta$ Lean } & \multicolumn{2}{|c|}{$\Delta F a t$} \\
\hline & Boys & Girls & Boys & Girls & Boys & Girls \\
\hline Lept & 0.0 & 0.15 & 0.15 & $0.40^{* *}$ & $-0.21^{* *}$ & $-0.27^{* *}$ \\
\hline Insulin 7 years & -0.03 & 0.10 & 0.02 & $0.27^{*}$ & 0.06 & $-0.35^{* * *}$ \\
\hline
\end{tabular}

Fat mass, leptin and insulin are natural log-transformed. $\Delta=$ change between 7 and 12 years. ${ }^{* *} P<0.01 ;{ }^{*} P<0.05$.
However, baseline leptin did not predict increases in height, and the main longitudinal associations were a positive correlation between change in fat and change in leptin, indicating that children increasing in adiposity secrete more leptin. Thus, leptin may reflect the ratio of fat to lean as well as energy stores per se, without driving subsequent tissue accretion patterns over time. One possibility is that leptin acts as a permissive signal for puberty, ${ }^{29}$ such that children progressing faster through puberty are both taller and also have lower leptin, as the energy is already being invested in the pubertal growth spurt.

In longitudinal analyses, change in adiposity was strongly associated with greater change in $I R$, but the causal direction of this association remains unclear. It may derive either through IR driving the accumulation of adipose tissue, ${ }^{30,31}$ or through weight gain and a lipogenic diet favouring IR to protect tissues against nutrient overload. ${ }^{32,33}$ Regardless of the causal direction of the association, it is clear that increases in adiposity are the dominant factor correlating with IR in this sample, however, gains in height and lean tissue also showed independent associations with increases in IR.

Although IR was associated in cross-sectional analyses with height and lean mass at every age in crude analyses, these associations disappeared once adjusted for adiposity, except in older girls. Thus, we assume that younger taller children have greater IR because they are also fatter, whereas older taller girls have greater IR independent of their fatness. Higher IR at 7 years predicted greater gains in lean mass in girls, but not greater increase in height, whereas the increase in IR between 7 and 12 years was correlated with increases in each of height, lean mass and fat mass. Although it remains difficult to interpret these data in terms of causality, our analyses demonstrate that growing taller and depositing more lean tissue are associated with increasing IR independent of adiposity, hence, fasting insulin by HOMA acts as a marker of growth as well as adiposity.

A limitation of our study is that we were only able to analyse two markers of cardiovascular risk, namely leptin and IR. We focused on these two outcomes precisely because they are simultaneously regulators of growth and body composition, while also predictive of future chronic disease risk. We cannot be sure that other cardiovascular risk markers would show similar associations. However, in a previous analysis of the ALSPAC cohort at age 9 years, we showed independent associations of height, lean mass and adiposity with blood pressure. ${ }^{18}$ Further work will be required to reveal how general the association of height and cardiovascular risk is in children. We also note that in adults, short stature is associated with greater cardiovascular risk. $^{34,35}$ This contrast may arise as taller children may be those growing faster during childhood, and not necessarily those who will be tallest in adulthood.

A second limitation was the sample size and the conducting of many statistical tests, which increases the possibility of reporting significant associations that actually arose through chance. Our

Table 4b. Longitudinal associations between body composition and metabolic risk from 7 to 12 years. Correlations of change in size, body composition and metabolic risk from 7 to 12 years

\begin{tabular}{|c|c|c|c|c|c|c|c|c|c|c|}
\hline & \multicolumn{2}{|c|}{$\triangle B M I$} & \multicolumn{2}{|c|}{$\Delta$ Lean } & \multicolumn{2}{|c|}{$\Delta$ Fat } & \multicolumn{2}{|c|}{$\Delta$ Leptin } & \multicolumn{2}{|c|}{$\begin{array}{l}\Delta \text { Insulin } \\
\text { resistance }\end{array}$} \\
\hline & Boys & Girls & Boys & Girls & Boys & Girls & Boys & Girls & Boys & Girls \\
\hline$\Delta \mathrm{BMI}$ & - & - & $0.46^{\#}$ & $0.58^{\#}$ & $0.81^{\#}$ & $0.70^{\#}$ & $0.67^{\#}$ & $0.57^{\#}$ & $0.38^{\#}$ & $0.47^{\#}$ \\
\hline$\Delta$ Lean & - & - & - & - & 0.15 & 0.08 & 0.04 & 0.18 & $0.29^{\#}$ & $0.39^{\#}$ \\
\hline$\Delta \mathrm{Fat}$ & - & - & - & - & - & - & $0.68^{\#}$ & $0.56^{\#}$ & $0.25^{* *}$ & $0.41^{\#}$ \\
\hline
\end{tabular}


Table 5. Partial correlations of change in size, body composition and metabolic risk from 7 to 12 years

\begin{tabular}{|c|c|c|}
\hline$\Delta$ Fat & $\begin{array}{cc}\Delta \text { Leptin adj. } & \Delta \text { Height } \\
\text { Boys } & \text { Girls } \\
0.68^{\#} & 0.55^{\#}\end{array}$ & $\begin{array}{cc}\Delta \text { Insulin adj. } & \Delta \text { Height } \\
\text { Boys } & \text { Girls } \\
0.20^{*} & 0.36^{\#}\end{array}$ \\
\hline$\Delta$ Height & $\begin{array}{cc}\Delta \text { Leptin adj. } & \Delta \text { Fat } \\
\text { Boys } & \text { Girls } \\
-0.09 & 0.09\end{array}$ & $\begin{array}{cc}\Delta \text { Insulin adj. } & \Delta \text { Fat } \\
\text { Boys } & \text { Girls } \\
0.20^{*} & 0.31^{* *}\end{array}$ \\
\hline$\Delta$ Fat & $\begin{array}{cc}\Delta \text { Leptin adj. } & \Delta \text { Lean } \\
\text { Boys } & \text { Girls } \\
0.68^{\#} & 0.57^{\#}\end{array}$ & $\begin{array}{cc}\Delta \text { Insulin adj. } & \Delta \text { Lean } \\
\text { Boys } & \text { Girls } \\
0.22^{*} & 0.41^{\#}\end{array}$ \\
\hline$\Delta$ Lean & $\begin{array}{ll}\Delta \text { Leptin adj. } & \Delta \text { Fat } \\
\text { Boys } & \text { Girls } \\
-0.08 & 0.19\end{array}$ & $\begin{array}{cc}\Delta \text { Insulin adj. } & \Delta \text { Fat } \\
\text { Boys } & \text { Girls } \\
0.21^{*} & 0.39^{\#}\end{array}$ \\
\hline
\end{tabular}

Fat mass, insulin and leptin are natural log-transformed. $\Delta=$ change between 7 and 12 years. ${ }^{\#} P<0.001 ;{ }^{*} P<0.01 ;{ }^{*} P<0.05$.

findings should therefore be confirmed using larger data sets, however, we note that our previous study, identifying independent associations of height and adiposity with blood pressure, was conducted in $>6500$ children. $^{18}$

Overall, our analyses indicate complexity in the associations between body size, growth rate, body composition and metabolic risk. Further work will need to be undertaken to tease out the effects in greater detail, but it is already clear from these data that associations of height or lean mass with CVD risk are not fully explained by their respective associations with adiposity. Rather, tall height and high lean mass are associated with CVD risk, independent of adiposity, and these associations evolve over time.

As both height and adiposity correlate with elevated metabolic risk, some indices such as BMI or FMI incorporate both of these sources of risk without distinguishing between them. ${ }^{26}$ Table 2 shows that height retains associations with IR, after adjusting for $\mathrm{BMI}$, but this information is lost when using BMI as an index of adiposity, as the rationale of the index is to 'remove any effect of height'. The same is true for FMI, which is generally treated only as an index of adiposity.

Previously, we noted that fat mass divided by height ${ }^{6}$ was independent of height in children aged 8 years. ${ }^{19}$ Using such an index, it is possible to assess the proportion of risk that derives from adiposity, independent of that deriving from height. This partitioning of risk has some benefits, because the factors (environmental or genetic) that account for variability in adiposity may not be identical with those that account for variability in growth. ${ }^{26}$ For example, linear growth appears most sensitive to environmental factors during fetal life and infancy, ${ }^{36,37}$ and many studies have associated early catch-up growth with subsequent adiposity. ${ }^{12,38-40}$ However, adiposity may be more sensitive to behaviours such as diet composition and physical activity behaviour throughout childhood. ${ }^{41-44}$

In general, the management of obesity favours loss of fat, but not a reduction in growth, ${ }^{45}$ hence, it is possible that the treatment of taller children might be inherently less successful at reducing metabolic risk than the treatment of shorter children. In Swedish adults, for example, the metabolic penalty (elevated blood pressure) for low birth weight was greater in individuals with both high BMI and greater height, and the highest blood pressures were found in those born small who were both obese and tall in adulthood. ${ }^{46}$

However, the partitioning of CVD risk into different components is also artificial, because of the complex ways in which growth in height and adiposity appear to be connected, in part by the very hormones that are used as markers of metabolic risk. As the hormones that index CVD risk also contribute to the regulation or growth and tissue deposition, BMI and FMI may be clinically useful ways to summarize metabolic risk, but not necessarily the best way to understand its aetiology.

Nevertheless, we suggest that such partitioning may be particularly helpful when addressing children approaching and undergoing puberty. At this time, elevations of CVD risk may relate in part to the faster tempo of growth during this period, and it may be valuable to quantify the component of risk attributable to adiposity, potentially more amenable to management. A novel statistical approach (SITAR) ${ }^{47}$ that can disentangle size, growth tempo and velocity might clarify these associations, for example, by adjusting the growth trajectory for the timing of puberty. Each approach therefore has some merits: BMI or FMI give a global index of CVD risk, integrating effects of growth and adiposity, whereas approaches using multiple regression analysis (simply entering terms separately) or specific indices (for example, fat normalized for height, or regression residuals) may tease out the contribution of growth versus adiposity to CVD risk, and clarify the opportunities for intervention.

\section{CONFLICT OF INTEREST}

The authors declare no conflict of interest.

\section{ACKNOWLEDGEMENTS}

We are grateful to Terence Wilkin and Brad Metcalf on behalf of the EarlyBird study for making their data available to us.

\section{REFERENCES}

1 Hursting SD. Obesity, energy balance, and cancer: a mechanistic perspective. Cancer Treat Res 2014; 159: 21-33.

2 Lewis GF. Devastating metabolic consequences of a life of plenty: focus on the dyslipidemia of overnutrition. Clin Invest Med 2013; 36: E242.

3 Power C, Lake JK, Cole TJ. Measurement and long-term health risks of child and adolescent fatness. Int J Obes 1997; 21: 507-526.

4 Reilly JJ, Kelly J. Long-term impact of overweight and obesity in childhood and adolescence on morbidity and premature mortality in adulthood: systematic review. Int J Obes 2011; 35: 891-898.

5 Reilly JJ, Methven E, McDowell ZC, Hacking B, Alexander D, Stewart Let al. Health consequences of obesity. Arch Dis Child 2003; 88: 748-752.

6 Goodman E, Dolan LM, Morrison JA, Daniels SR. Factor analysis of clustered cardiovascular risks in adolescence: obesity is the predominant correlate of risk among youth. Circulation 2005; 111: 1970-1977.

7 Janssen I, Katzmarzyk PT, Srinivasan SR, Chen W, Malina RM, Bouchard C et al. Utility of childhood BMI in the prediction of adulthood disease: comparison of national and international references. Obes Res 2005; 13: 1106-1115.

8 Blüher S, Molz E, Wiegand S, Otto KP, Sergeyev E, Tuschy Set al. Body mass index, waist circumference, and waist-to-height ratio as predictors of cardiometabolic risk in childhood obesity depending on pubertal development. J Clin Endocrinol Metab 2013; 98: 3384-3393.

9 Wells JC. A Hattori chart analysis of body mass index in infants and children Int J Obes 2000; 24: 325-329.

10 lbáñez L, Ong K, Dunger DB, de Zegher F. Early development of adiposity and insulin resistance after catch-up weight gain in small-for-gestational-age children. J Clin Endocrinol Metab 2006; 91: 2153-2158.

11 Lawlor DA, Benfield L, Logue J, Tilling K, Howe LD, Fraser A et al. Association between general and central adiposity in childhood, and change in these, with cardiovascular risk factors in adolescence: prospective cohort study. BMJ 2010; 341: c6224.

12 Dulloo AG, Jacquet J, Seydoux J, Montani JP. The thrifty 'catch-up fat' phenotype: its impact on insulin sensitivity during growth trajectories to obesity and metabolic syndrome. Int J Obes 2006; 30 (Suppl 4): S23-S35.

13 Pietrobelli A, Faith MS, Allison DB, Gallagher D, Chiumello G, Heymsfield SB. Body mass index as a measure of adiposity among children and adolescents: a validation study. J Pediatr 1998; 132: 204-210.

14 Van Itallie TB, Yang MU, Heymsfield SB, Funk RC, Boileau RA. Height-normalized indices of the body's fat-free mass and fat mass: potentially useful indicators of nutritional status. Am J Clin Nutr 1990; 52: 953-959. 
15 Wells JC. A critique of the expression of paediatric body composition data. Arch Dis Child 2001; 85: 67-72.

16 Roubenoff R. Sarcopenia and its implications for the elderly. Eur J Clin Nutr 2000; 4 (Suppl 3): S40-S47.

17 Unni US, Ramakrishnan G, Raj T, Kishore RP, Thomas T, Vaz Met al. Muscle mass and functional correlates of insulin sensitivity in lean young Indian men. Eur J Clin Nutr 2009; 63: 1206-1212.

18 Grijalva-Eternod CS, Lawlor DA, Wells JC. Testing a capacity-load model for hypertension: disentangling early and late growth effects on childhood blood pressure in a prospective birth cohort. PLoS One 2013; 8: e56078.

19 Wells JC, Cole TJ. ALSPAC study team Adjustment of fat-free mass and fat mass for height in children aged 8 y. Int J Obes Relat Metab Disord 2002; 26: 947-952.

20 Wells JC, Victora CG. Indices of whole-body and central adiposity for evaluating the metabolic load of obesity. Int J Obes 2005; 29: 483-489.

21 Cole TJ. Weight/height ${ }^{p}$ compared to weight/height ${ }^{2}$ for assessing adiposity in childhood: influence of age and bone age on $\mathrm{p}$ during puberty. Ann Hum Biol 1986; 13: 433-451.

22 Cole TJ, Henson GL, Tremble JM. Colley NV.Birthweight for length: ponderal index, body mass index or Benn index? Ann Hum Biol 1997; 24: 289-298.

23 Cole, TJ. Weight-stature indices to measure underweight, over- weight and obesity. Anthropometric Assessment of Nutritional Status. Wiley Liss: New York, 1991; 83-111.

24 Heymsfield SB, Gallagher D, Mayer L, Beetsch J, Pietrobelli A. Scaling of human body composition to stature: new insights into body mass index. Am J Clin Nutr 2007; 86: 82-91.

25 Metcalf BS, Hosking J, Frémeaux AE, Jeffery AN, Voss LD, Wilkin TJ. BMI was right all along: taller children really are fatter (implications of making childhood BMI independent of height) EarlyBird 48. Int J Obes 2011; 35: 541-547.

26 Wells JC, Cole TJ. Disentangling the size and adiposity components of obesity. Int J Obes 2011; 35: 548-549.

27 Jéquier E. Leptin signaling, adiposity, and energy balance. Ann N Y Acad Sci 2002; 967: 379-388.

28 Blum WF, Englaro P, Hanitsch S, Juul A, Hertel NT, Müller Jet al. Plasma leptin levels in healthy children and adolescents: dependence on body mass index, body fat mass, gender, pubertal stage, and testosterone. J Clin Endocrinol Metab 1997; 82: 2904-2910.

29 Lustig RH. Childhood obesity: behavioral aberration or biochemical drive? Reinterpreting the First Law of Thermodynamics. Nat Clin Pract Endocrinol Metab 2006; 2: 447-458.

30 DeFronzo RA, Ferrannini E. Insulin resistance. A multifaceted syndrome responsible for NIDDM, obesity, hypertension, dyslipidemia, and atherosclerotic cardiovascular disease. Diabetes Care 1991; 14: 173-194.

31 Catalano PM, Presley L, Minium J, Hauguel-de Mouzon S. Fetuses of obese mothers develop insulin resistance in utero. Diabetes Care 2009; 32: 1076-1080.

32 Hoehn KL, Salmon AB, Hohnen-Behrens C, Turner N, Hoy AJ, Maghzal GJ et al. Insulin resistance is a cellular antioxidant defense mechanism. Proc Natl Acad Sci USA 2009; 106: 17787-17792.

33 Lustig RH. Which comes first? The obesity or the insulin? The behavior or the biochemistry?. J Pediatr 2008; 152: 601-602.
34 Waaler HT. Height, weight and mortality. The Norwegian experience. Acta Med Scand Suppl 1984; 679: 1-56.

35 Davey Smith G, Hart C, Upton M, Hole D, Gillis C, Watt G et al. Height and risk of death among men and women: aetiological implications of associations with cardiorespiratory disease and cancer mortality. J Epidemiol Community Health 2000; 54: 97-103.

36 Smith DW, Truog W, Rogers JE, Greitzer LJ, Skinner AL, McCann JJ et al. Shifting linear growth during infancy: illustration of genetic factors in growth from fetal life through infancy. J Pediatr 1976; 89: 225-230.

37 Wells JC, Hallal PC, Wright A, Singhal A, Victora CG. Fetal, infant and childhood growth: relationships with body composition in Brazilian boys aged 9 years. Int $J$ Obes 2005; 29: 1192-1198.

38 Ong KK, Ahmed ML, Emmett PM, Preece MA, Dunger DB. Association between postnatal catch-up growth and obesity in childhood: prospective cohort study. BMJ 2000; 320: 967-971.

39 Modi N, Thomas EL, Harrington TA, Uthaya S, Doré CJ, Bell JD. Determinants of adiposity during preweaning postnatal growth in appropriately grown and growth-restricted term infants. Pediatr Res 2006; 60: 345-348.

40 Chomtho S, Wells JC, Williams JE, Davies PS, Lucas A, Fewtrell MS. Infant growth and later body composition: evidence from the 4-component model. Am J Clin Nutr 2008; 87: 1776-1784.

41 Fiorito LM, Marini M, Francis LA, Smiciklas-Wright H, Birch LL. Beverage intake of girls at age 5 y predicts adiposity and weight status in childhood and adolescence. Am J Clin Nutr 2009; 90: 935-942.

42 Ambrosini GL, Emmett PM, Northstone K, Howe LD, Tilling K, Jebb SA. Identification of a dietary pattern prospectively associated with increased adiposity during childhood and adolescence. Int J Obes 2012; 36: 1299-1305.

43 Staiano AE, Harrington DM, Broyles ST, Gupta AK, Katzmarzyk PT. Television, adiposity, and cardiometabolic risk in children and adolescents. Am J Prev Med 2013; 44: 40-47.

44 Rennie KL, Livingstone MB, Wells JC, McGloin A, Coward WA, Prentice AM et al. Association of physical activity with body-composition indexes in children aged 6-8 y at varied risk of obesity. Am J Clin Nutr 2005; 82: 13-20.

45 Barlow SE, Dietz WH. Obesity evaluation and treatment: expert committee recommendations. The Maternal and Child Health Bureau, Health Resources and Services Administration and the Department of Health and Human Services. Pediatrics 1998; 102: E29.

46 Leon DA, Koupilova I, Lithell HO, Berglund L, Mohsen R, Vagero D et al. Failure to realise growth potential in utero and adult obesity in relation to blood pressure in 50 year old Swedish men. BMJ 1996; 312: 401-406.

47 Cole TJ, Donaldson MD, Ben-Shlomo Y. SITAR - a useful instrument for growth curve analysis. Int J Epidemiol 2010; 39: 1558-1566.



This work is licensed under a Creative Commons Attribution 3.0 Unported License. To view a copy of this license, visit http:// creativecommons.org/licenses/by/3.0/

Supplementary Information accompanies this paper on International Journal of Obesity website (http://www.nature.com/ijo) 